\title{
Article \\ Comparison of Physical, Occupational, and Sociocognitive Characteristics of Corporate and Private Taxi Drivers in Korea
}

\author{
JongSun Ok ${ }^{1}\left[\right.$, Hyeongsu Kim ${ }^{2, *}$ a and Kyonghwa Kang ${ }^{3(\mathbb{D}}$ \\ 1 Department of Nursing, Konkuk University, Chungju 27478, Korea; sokei@kku.ac.kr \\ Department of Preventive Medicine, School of Medicine, Konkuk University, Seoul 05029, Korea \\ 3 Department of Nursing, Chungwoon University, Hongseong 32244, Korea; kh_kang@chungwoon.ac.kr \\ * Correspondence: mubul@kku.ac.kr; Tel.: +82-2-2030-7942
}

\section{check for}

updates

Citation: Ok, J.; Kim, H.; Kang, K. Comparison of Physical,

Occupational, and Sociocognitive Characteristics of Corporate and

Private Taxi Drivers in Korea.

Healthcare 2021, 9, 224. https://

doi.org/10.3390/healthcare9020224

Received: 29 December 2020

Accepted: 14 February 2021

Published: 17 February 2021

Publisher's Note: MDPI stays neutral with regard to jurisdictional claims in published maps and institutional affiliations.

Copyright: (c) 2021 by the authors. Licensee MDPI, Basel, Switzerland. This article is an open access article distributed under the terms and conditions of the Creative Commons Attribution (CC BY) license (https:/ / creativecommons.org/licenses/by/ $4.0 /)$.

\begin{abstract}
Taxis are a form of public transport which is very closely related to the safety of the public. Although private and corporate taxis have quite different characteristics, there have only been a few studies comparing the characteristics of corporate and private taxis. Moreover, among various characteristics, research was conducted mainly focusing on occupational characteristics. This study was undertaken to compare various physical, occupational, and sociocognitive characteristics of corporate and private taxi drivers. A descriptive cross-sectional study was conducted from 22 August to 11 September 2018. The subjects of this study were 960 corporate and private taxi drivers over 30 years old in Seoul to compare the means and association between private and corporate taxi drivers characteristics. In terms of the physical characteristics, corporate taxi drivers' general physical health status was worse. In terms of the occupational characteristics, corporate taxi drivers had a high working intensity, and the incidence rate of traffic accidents and near misses was also high. This comparison of the characteristics of corporate and private taxis is expected to serve as evidence for developing tailored policies and programs to improve the health of corporate and private taxi drivers.
\end{abstract}

Keywords: occupational health; motor vehicle; health risk behavior

\section{Introduction}

Taxis are a form of public transport, and taxi drivers have unique physical, socioeconomic, occupational, and emotional characteristics that distinguish them from other employees. Compared to white-collar workers, taxi drivers complained of more musculoskeletal symptoms related to the shoulder and back, and the rate of psychological stress such as anxiety and agitation was higher [1]. In addition, taxi drivers reported having less sleep time than drivers of city buses, which represent a similar type of commercial vehicle, and they also reported that the driving time, driving distance, and number of near misses were higher [2]. In particular, taxi drivers are reported to have a greater burden in their efforts to achieve the target for daily taxi driving. This is because the wage of the taxi driver increases upon driving the taxi a longer distance within a specified time [2]. Taxi fares in Korea are only one-third of the fares based on distance and time compared to other Organization for Economic Cooperation and Development (OECD) countries. In addition, since taxi-only vehicles are not used, maintenance costs are high due to the purchase of commercial vehicles [3].

In 2020, the percentages of private taxis and corporate taxis in Korea were $65.8 \%$ and $34.2 \%$, respectively. In other words, there are almost twice as many private taxis in Korea as corporate taxis [4]. This is the highest level compared to the percentages of private taxis by country as of 2012, which are 35\% in Japan, $43 \%$ in the United Kingdom, and $42 \%$ in the United States [5]. Private taxis and corporate taxis have quite different characteristics. In order to qualify as a private taxi driver who can take over a private taxi, taxi drivers must have more than 5 years of accident-free driving, as well as corporate taxi driver experience. However, with the revision of the Enforcement Rules of the Passenger 
Transport Business Act in 2021, the standards for obtaining private taxi qualifications were eased, and it is now possible to obtain private taxi qualifications if you have 5 years of accident-free driving experience in a personal car [6]. Although the amount varies depending on the region, approximately KRW 80 million to 100 million is required for the purchase of a private taxi, and it is impossible to sell the acquisition within the next five years [6]. In the Korean health insurance system, private taxi drivers become self-employed health insurance members, and corporate taxi drivers become employee health insurance members because they belong to a taxi company. In the case of employee health insurance, insurance premiums are calculated only on the basis of monthly salary, while self-employed health insurance is calculated by considering monthly income and properties such as real estate and automobiles [7]. Therefore, private taxi drivers have a higher burden of health insurance premiums than corporate taxi drivers. Unlike private taxis, corporate taxis are required to make base payments to operate a taxi [8]. This refers to the taxi rental fee for $12 \mathrm{~h}$ a day. As the taxi fare increases, the base payments also increase. However, due to the taxi fare increase, taxi passengers reduce their use of taxis, and the income of taxi drivers decreases further. In addition, corporate taxi drivers have to work shifts in the morning and afternoon [8].

However, since there is more interest in traffic accidents and driving behaviors caused by taxis, most previous studies simply presented the characteristics of taxi drivers. In particular, only a few studies investigated the physical characteristics of taxi drivers regardless of the type of taxi driver (corporate or private) [8-10]. Furthermore, most of these studies only mentioned occupational characteristics among the various characteristics of taxi drivers, and they had a limitation in analyzing tachometer data [8-10]. In particular, there are limitations in the investigation of the social, economic, and emotional characteristics of taxi drivers with tachometer data analysis.

Unlike workers in other occupations who gather and work in certain places, taxi drivers spend a lot of time outside; thus, it tends to be difficult to gather information about their physical and psychosocial health-related status. However, since the physical and psychosocial health-related status of taxi drivers is very closely related to the safety of taxi passengers, it is important to investigate this to prepare measures to improve the health of taxi drivers. Therefore, in this study, we compared various physical, occupational, and sociocognitive characteristics of corporate and private taxi drivers in Seoul. This comparison of the characteristics of corporate and private taxis is expected to serve as evidence for developing policies and programs to improve the health of corporate and private taxi drivers.

\section{Materials and Methods}

\subsection{Study Design and Subjects}

This study is a descriptive cross-sectional study that compares physical, occupational, and sociocognitive characteristics between corporate taxi drivers and private taxi drivers. The subjects of this study were corporate and private taxi drivers over 30 years old driving taxis in Seoul.

\subsection{Measurements and Variables}

\subsubsection{Measurements}

The survey questions were developed through meetings between the researchers and outside experts. According to existing research results on taxi drivers, this research questionnaire constituted a survey of taxi drivers' personal history, basic data related to taxi driving, and questions on the health status of taxi drivers. Through this, we aimed to investigate various environmental risk factors for taxi drivers. To evaluate the adequacy of the developed questions, two groups of private taxi drivers and corporate taxi drivers were selected. A preliminary questionnaire was conducted with them, collecting their opinions, and the final questions were confirmed by revising and supplementing the questions. 


\subsubsection{Variables}

The questionnaire with a self-report form was composed of questions to understand the physical, occupational, and sociocognitive characteristics of corporate and private taxi drivers.

First, the physical characteristics variables were age, body mass index (BMI), physical health discomfort, duration of physical health discomfort over the last 2 weeks (days), general physical health status (very good, good, usual, bad, or very bad), the number and types of chronic disease, and the effects of chronic diseases on taxi driving (no effect, generally no effect, usually, mostly influences, or greatly influences). Chronic diseases were those diagnosed by physicians and currently being treated by regularly visiting a medical institution. As chronic diseases, diseases of the circulatory system, respiratory system, endocrine system, and musculoskeletal system were investigated.

The occupational characteristic variables were taxi driving work experience, number of working days per week, daily driving time, daily mileage, number of night shifts per month (working after 10 p.m.), number of traffic accidents or near misses in the last 3 years, and the relationship between traffic accidents (or near misses) and chronic diseases (not relevant, mostly not relevant, usually, mostly relevant, or very relevant). Near misses are cases in which a traffic accident may have occurred but did not lead to a direct traffic accident with personal and material damages.

The sociocognitive characteristics variables were marital status (unmarried, married with spouse, or married with no spouse (e.g., divorced)), number of dependent family members, monthly household income, income satisfaction (large enough, enough, average, insufficient, or very insufficient), and cognitive impairment. The Korean Dementia Screening Questionnaire (KDSQ) was used to evaluate cognitive impairment. This tool is a three-point scale composed of a total of 15 questions, with the score ranging from 0 to 30 points. The cutoff point of this tool is 8 points. A score of 2 or less is classified as no cognitive impairment (CN: cognitively normal), a score of 3-7 points is classified as mild cognitive impairment (MCI), and a score of 8 points or more is classified as dementia. This is a cognitive impairment evaluation tool that is not affected by education, age, or gender. At the time of the tool's development, the sensitivity was $79 \%$ and the specificity was $80 \%$ [11].

\subsection{Data Collection and Research Ethics}

The survey on corporate and private taxi drivers working in Seoul was conducted with the Korea Transportation Safety Authority, Korea National Joint Conference of Taxi Association, Korea National Federation of Private Taxi Transportation Association, Korea National Federation of Taxi Workers' Unions Federation, and Korea National Federation of Democratic Taxi Workers' Unions.

The survey was approved by the Institutional Review Board/Ethnics committee of Konkuk University (IRB 7001355-202011-E-127). The survey subjects who agreed to the purpose of the study participated, and the survey period was from 22 August to 11 September 2018. The survey was conducted with a self-report method, with a total of 965 participants. Excluding five female respondents, a total of 960 people (501 corporate taxi drivers, 459 private taxi drivers) were analyzed.

\subsection{Data Analysis}

The collected data were analyzed using the statistical program $\mathrm{R}$ ( $\mathrm{R}$ Foundation for Statistical Computing, Vienna, Austria). Descriptive statistics on physical, occupational, and sociocognitive characteristics of the study participants were presented as frequencies and percentages or means and standard deviations. The chi-square test and $t$-test were used to compare physical, occupational, and sociocognitive characteristics between the two groups of private and corporate taxi drivers. A significance level of 0.05 was set as the criterion for significance. 


\section{Results}

\subsection{Comparison of Physical Characteristics between Corporate and Private Taxi Drivers}

Table 1 shows a comparison of the physical characteristics between corporate and private taxi drivers. The average age of private taxi drivers was $63.36 \pm 7.67$ years, which was higher than that of corporate taxi drivers, at $60.89 \pm 7.76$ years $(t=-4.90, p<0.001)$. The average BMI $\left(\mathrm{kg} / \mathrm{m}^{2}\right)$ was similar for corporate and private taxi drivers, at $24.64 \pm 3.05$ and $24.98 \pm 2.62$, respectively $(t=-1.72, p=0.086)$.

Table 1. Physical characteristics of corporate and private taxi drivers.

\begin{tabular}{|c|c|c|c|c|}
\hline Item & $\begin{array}{c}\text { Corporate Taxi } \\
\mathrm{M} \pm \mathrm{SD} \text { or } N(\%)\end{array}$ & $\begin{array}{c}\text { Private Taxi } \\
\mathrm{M} \pm \mathrm{SD} \text { or } N(\%)\end{array}$ & $t$ or $\chi^{2}$ & $p$ \\
\hline No. of subjects & $501(52.2)$ & $459(47.8)$ & & \\
\hline Age & $60.89 \pm 7.76$ & $63.36 \pm 7.67$ & -4.90 & $<0.001$ \\
\hline$\leq 40 \mathrm{~s}$ & $38(7.8)$ & $22(4.9)$ & 16.72 & $<0.001$ \\
\hline$\overline{50 s}$ & $142(29.0)$ & $102(22.9)$ & & \\
\hline $60 \mathrm{~s}$ & $254(51.8)$ & $234(52.5)$ & & \\
\hline$\geq 70 \mathrm{~s}$ & $56(11.4)$ & $88(19.7)$ & & \\
\hline $\mathrm{BMI}\left(\mathrm{kg} / \mathrm{m}^{2}\right)$ & $24.64 \pm 3.05$ & $24.98 \pm 2.62$ & -1.72 & 0.086 \\
\hline$<25$ & $255(59.3)$ & $218(51.4)$ & 6.45 & 0.040 \\
\hline $25-30$ & $158(36.8)$ & $192(45.3)$ & & \\
\hline$\geq 30$ & $17(3.9)$ & $14(3.3)$ & & \\
\hline \multicolumn{5}{|l|}{ Physical health discomfort in the last 2 weeks } \\
\hline Yes & $106(22.6)$ & $24(5.4)$ & 54.40 & $<0.001$ \\
\hline $\begin{array}{l}\text { The duration of health discomfort in the } \\
\text { last } 2 \text { weeks (days) }\end{array}$ & $0.99 \pm 2.36$ & $0.24 \pm 1.35$ & 5.89 & $<0.001$ \\
\hline \multicolumn{5}{|l|}{ General physical health status } \\
\hline Good and very good & 177 (35.6) & $251(54.9)$ & 81.30 & $<0.001$ \\
\hline Usual & $209(42.1)$ & $189(41.4)$ & & \\
\hline Bad and very bad & $111(22.3)$ & $17(3.7)$ & & \\
\hline \multicolumn{5}{|l|}{ Taxi driving effect of having chronic diseases } \\
\hline Not affected & $217(56.5)$ & $280(84.9)$ & 95.60 & $<0.001$ \\
\hline Usually & $56(14.5)$ & $42(12.7)$ & & \\
\hline Influential & $11(29.0)$ & $8(2.4)$ & & \\
\hline Number of chronic diseases & $1.43 \pm 1.87$ & $0.76 \pm 1.11$ & 6.55 & $<0.001$ \\
\hline \multicolumn{5}{|l|}{ Types of chronic diseases } \\
\hline \multicolumn{5}{|l|}{ HTN } \\
\hline Yes & $188(38.5)$ & $151(33.6)$ & 2.29 & 0.130 \\
\hline \multicolumn{5}{|l|}{$\mathrm{DM}$} \\
\hline Yes & $123(25.2)$ & $73(16.2)$ & 10.89 & 0.001 \\
\hline \multicolumn{5}{|l|}{ COPD and asthma } \\
\hline Yes & $41(8.4)$ & $5(1.1)$ & 25.14 & $<0.001$ \\
\hline \multicolumn{5}{|l|}{ Sleep disorder } \\
\hline Yes & $46(9.4)$ & $7(1.6)$ & 25.75 & $<0.001$ \\
\hline \multicolumn{5}{|l|}{ Anxiety, depression, and panic disorder } \\
\hline Yes & $24(4.9)$ & $5(1.1)$ & 10.09 & 0.001 \\
\hline \multicolumn{5}{|l|}{ Hearing loss } \\
\hline Yes & $35(7.2)$ & $13(2.9)$ & 7.99 & 0.005 \\
\hline \multicolumn{5}{|l|}{ Arthritis } \\
\hline Yes & $77(15.8)$ & $19(4.2)$ & 32.79 & $<0.001$ \\
\hline \multicolumn{5}{|l|}{ Disc disease } \\
\hline Yes & $70(14.3)$ & $28(6.2)$ & 15.65 & $<0.001$ \\
\hline
\end{tabular}

$\mathrm{M}=$ mean; $\mathrm{SD}$ = standard deviation; $\mathrm{BMI}=$ body mass index; $\mathrm{HTN}$ = hypertension; $\mathrm{DM}$ = diabetes mellitus; $\mathrm{COPD}=$ chronic obstructive pulmonary disease.

In the case of the percentage of those experiencing physical health discomfort in the last 2 weeks and the physical health discomfort period for the last 2 weeks, private taxi drivers revealed results of $5.4 \%$ and $0.24 \pm 1.35$ days, respectively, and corporate taxi drivers revealed results of $23 \%$ and $0.99 \pm 2.36$ days, respectively $\left(\chi^{2}=54.40, p<0.001\right.$; 
$t=5.89, p<0.001)$. In other words, corporate taxi drivers had higher rates of physical health discomfort than private taxi drivers, and the period of physical health discomfort was longer than that for private taxi drivers.

The percentage of private taxi drivers who responded that their general physical health status was "bad" was only $3.7 \%$, while the response rate of corporate taxi drivers was $22.3 \%$, almost seven times higher than that of private taxi drivers $\left(\chi^{2}=81.30\right.$, $p<0.001)$. The number of chronic diseases in corporate taxi drivers was $1.43 \pm 1.87$, whereas there were $0.76 \pm 1.11$ chronic diseases in private taxi drivers $(t=6.55, p<0.001)$. The highest percentage of chronic diseases was occupied by hypertension (HTN), with $38.5 \%$ of corporate taxi drivers and $33.6 \%$ of private taxi drivers $\left(\chi^{2}=2.29, p=0.130\right)$. In addition, the rate of chronic obstructive pulmonary disease (COPD) and asthma was $1.1 \%$ for private taxi drivers, whereas it was $8.4 \%$ for corporate taxi drivers $\left(\chi^{2}=25.14\right.$, $p<0.001)$.

\subsection{Comparison of Occupational Characteristics between Corporate and Private Taxi Drivers}

Table 2 shows a comparison of occupational characteristics between corporate and private taxi drivers. The taxi driving work experience was $13.86 \pm 8.78$ years for corporate taxi drivers and $24.20 \pm 12.17$ years for private taxi drivers $(t=-15.15, p<0.001)$. The number of working days per week was $5.89 \pm 0.80$ days for corporate taxi drivers and $4.60 \pm 1.02$ days for private taxi drivers $(t=20.94, p<0.001)$. The average daily driving time and average daily mileage were $11.88 \pm 2.80$ days and $230.25 \pm 68.51 \mathrm{~km}$ for private taxi drivers and $10.07 \pm 1.52$ days and $261.65 \pm 85.24 \mathrm{~km}$ for corporate taxi drivers, respectively $(t=-12.32, p<0.001 ; t=6.24, p<0.001)$. The average number of night shifts per month was $10.14 \pm 8.04$ days for private taxi drivers and $12.36 \pm 7.52$ days for corporate taxi drivers $(t=4.23, p<0.001)$.

Table 2. Occupational characteristics of corporate and private taxi drivers.

\begin{tabular}{|c|c|c|c|c|}
\hline Item & $\begin{array}{c}\text { Corporate Taxi } \\
\mathrm{M} \pm \mathrm{SD} \text { or } N(\%)\end{array}$ & $\begin{array}{c}\text { Private Taxi } \\
\mathrm{M} \pm \mathrm{SD} \text { or } N(\%)\end{array}$ & $t$ or $\chi^{2}$ & $p$ \\
\hline Taxi driving work experience (years) & $13.86 \pm 8.78$ & $24.20 \pm 12.17$ & -15.15 & $<0.001$ \\
\hline Driving frequency (days/week) & $5.89 \pm 0.80$ & $4.60 \pm 1.02$ & 20.94 & $<0.001$ \\
\hline Daily driving time(h/day) & $10.07 \pm 1.52$ & $11.88 \pm 2.80$ & -12.32 & $<0.001$ \\
\hline Daily mileage (km) & $261.65 \pm 85.24$ & $230.25 \pm 68.51$ & 6.24 & $<0.001$ \\
\hline Number of night shifts (per month) & $12.36 \pm 7.52$ & $10.14 \pm 8.04$ & 4.23 & $<0.001$ \\
\hline \multicolumn{5}{|l|}{ Traffic accidents in the last 3 years } \\
\hline Yes & $229(51.0)$ & $122(28.5)$ & 45.27 & $<0.001$ \\
\hline \multicolumn{5}{|l|}{ Near misses in the last 3 years } \\
\hline Yes & $211(51.5)$ & $106(27.7)$ & 45.71 & $<0.001$ \\
\hline The number of traffic accidents in the last 3 years & $2.00 \pm 1.45$ & $1.70 \pm 1.58$ & 1.68 & 0.093 \\
\hline 1 & $115(51.1)$ & $70(64.8)$ & 12.42 & 0.006 \\
\hline 2 & $44(19.6)$ & $24(22.2)$ & & \\
\hline 3 & $47(20.9)$ & $7(6.5)$ & & \\
\hline$\geq 4$ & $19(8.4)$ & $7(6.5)$ & & \\
\hline The number of near misses in the last 3 years & $4.23 \pm 3.82$ & $2.72 \pm 2.61$ & 3.47 & $<0.001$ \\
\hline $1-2$ & $96(47.8)$ & $62(66.0)$ & 61.29 & $<0.001$ \\
\hline $3-4$ & $32(15.9)$ & $13(13.8)$ & & \\
\hline $5-6$ & $28(13.9)$ & $12(12.8)$ & & \\
\hline$\geq 7$ & $45(22.4)$ & $7(7.4)$ & & \\
\hline \multicolumn{5}{|c|}{ Relationship between having chronic diseases and traffic accidents or near misses } \\
\hline Not relevant & $269(64.8)$ & $292(89.3)$ & 74.95 & $<0.001$ \\
\hline Usually & $33(8.0)$ & $23(7.0)$ & & \\
\hline Relevant & $113(27.2)$ & $12(3.7)$ & & \\
\hline
\end{tabular}

The incidence rate and number of traffic accidents in the last 3 years were $28.5 \%$ and $1.70 \pm 1.58$ cases for private taxi drivers, respectively, and $51.0 \%$ and $2.00 \pm 1.45$ cases for corporate taxi drivers, respectively $\left(\chi^{2}=45.27, p<0.001 ; t=1.68, p=0.093\right)$. The incidence 
rate and number of near misses in the last 3 years were $27.7 \%$ and $2.72 \pm 2.61$ cases for private taxi drivers, respectively, and $51.5 \%$ and $4.23 \pm 3.82$ cases for corporate taxi drivers, respectively $\left(\chi^{2}=45.71, p<0.001 ; t=3.47, p<0.001\right)$. The percentage of those responding that traffic accidents (or near misses) and chronic diseases were "related" was 3.7\% of private taxi drivers. On the other hand, $27.2 \%$ of corporate taxi drivers answered that traffic accidents (or near misses) and chronic diseases were "related", which was seven times higher than that of private taxi drivers $\left(\chi^{2}=74.95, p<0.001\right)$.

\subsection{Comparison of Sociocognitive Characteristics between Corporate and Private Taxi Drivers}

Table 3 shows a comparison of sociocognitive characteristics between corporate and private taxi drivers. In terms of marital status, the percentage of those married was as high as $92.5 \%$ for private taxi drivers, but the rate of being single, divorced, or separated was as high as $29 \%$ for corporate taxi drivers $\left(\chi^{2}=68.13, p<0.001\right)$. The proportion of those with five or more dependent family members was $5.1 \%$ for private taxi drivers and $8.7 \%$ for corporate taxi drivers $\left(\chi^{2}=7.48, p=0.024\right)$. In terms of household monthly income, the ratio of household income of KRW 1-9 million a month was the highest for both corporate and private taxi drivers $\left(\chi^{2}=14.30, p=0.003\right)$. In terms of income satisfaction, the proportion of private taxi drivers who answered "there is not enough income" was $50 \%$, whereas this result was over $70 \%$ for corporate taxi drivers $\left(\chi^{2}=46.93, p<0.001\right)$. The average score for cognitive function was $1.43 \pm 0.71$ points for corporate taxi drivers and $1.09 \pm 0.32$ points for private taxi drivers $(t=9.24, p<0.001)$.

Table 3. Sociocognitive characteristics of corporate and private taxi drivers. KRW, South Korean won.

\begin{tabular}{|c|c|c|c|c|}
\hline Item & $\begin{array}{c}\text { Corporate Taxi } \\
\mathrm{M} \pm \mathrm{SD} \text { or } N(\%)\end{array}$ & $\begin{array}{c}\text { Private Taxi } \\
\mathrm{M} \pm \mathrm{SD} \text { or } N(\%)\end{array}$ & $t$ or $\chi^{2}$ & $p$ \\
\hline \multicolumn{5}{|l|}{ Marital status } \\
\hline Married (having a spouse) & $344(71.0)$ & $407(92.5)$ & 68.13 & $<0.001$ \\
\hline Other (single, separated, divorced, etc.) & $140(29.0)$ & $33(7.5)$ & & \\
\hline $\begin{array}{l}\text { Number of dependent family member (adulthood } \\
\text { and underage) }\end{array}$ & $2.84 \pm 1.20$ & $2.67 \pm 1.04$ & 2.26 & 0.024 \\
\hline $1-2$ & $204(49.1)$ & $236(57.3)$ & 7.48 & 0.024 \\
\hline $3-4$ & $175(42.2)$ & $155(37.6)$ & & \\
\hline$\geq 5$ & $36(8.7)$ & $21(5.1)$ & & \\
\hline \multicolumn{5}{|l|}{ Household income (per month) } \\
\hline$<100($ KRW 10,000) & $93(21.7)$ & $62(15.0)$ & 14.30 & 0.003 \\
\hline 100-199 (KRW 10,000) & $218(51.0)$ & $198(47.9)$ & & \\
\hline 200-299 (KRW 10,000) & $83(19.4)$ & $94(22.8)$ & & \\
\hline$\geq 300(\mathrm{KRW} 10,000)$ & $34(7.9)$ & $59(14.3)$ & & \\
\hline \multicolumn{5}{|l|}{ Income Satisfaction } \\
\hline Enough & $11(2.2)$ & $22(4.9)$ & 46.93 & $<0.001$ \\
\hline Average & $126(25.7)$ & $201(44.7)$ & & \\
\hline Not enough (insufficient) & $354(72.1)$ & $227(50.4)$ & & \\
\hline Cognition & $1.43 \pm 0.71$ & $1.09 \pm 0.32$ & 9.24 & $<0.001$ \\
\hline $\mathrm{CN}$ & $348(70.2)$ & $412(91.8)$ & 78.73 & $<0.001$ \\
\hline MCI & $83(16.7)$ & $33(7.3)$ & & \\
\hline Dementia & $65(13.1)$ & $4(0.9)$ & & \\
\hline
\end{tabular}

KDSQ (Korean Dementia Screening Questionnaire); CN = cognitively normal (KDSQ $\leq 2$ ); $\mathrm{MCI}=$ mild cognitive impairment (KDSQ 3-7); dementia (KDSQ $\geq 8$ ). One million KRW $=895$ United states dollars (USD) $=766$ euros (EUR), according to exchange rate as of 2018.

\section{Discussion}

This study attempted to present objective evidence for establishing health management policies for taxi drivers by comparing physical, occupational, and sociocognitive characteristics between corporate and private taxi drivers.

First of all, according to the physical characteristics of this study, the average age and proportion of taxi drivers over 70 years old were lower for corporate taxi drivers than 
private taxi drivers. Nevertheless, the percentage of corporate taxi drivers who experienced physical health discomfort in the last 2 weeks was higher than that of private taxi drivers, their general physical health status was worse than that of private taxi drivers, and the number of chronic diseases was also higher than that of private taxi drivers. It is thought that this is related to the occupational characteristics of corporate taxi drivers. In fact, as shown in this study, corporate taxi drivers had more working days per week and greater average daily mileage than private taxi drivers, as well as more frequent night shifts per month. This means that, although private taxi drivers were older than corporate taxi drivers, private taxi drivers can adjust their driving time according to their physical health status. On the other hand, corporate taxi drivers have to work shifts and pay the base payments to operate their taxis; thus, it is thought that there may be limitations in effectively managing the physical health problems of corporate taxi drivers. Corporate taxi drivers who are members of employee health insurance are considered to have a higher rate of diagnosis of chronic diseases through medical institutions because they are less burdened with medical expenses than private taxi drivers who are members of self-employed health insurance. In particular, it is thought that the rate of chronic diseases is relatively high in corporate taxi drivers because health checkups are essential to work as a corporate taxi driver. However, it is necessary to further investigate the onset and complications of chronic diseases in taxi drivers.

In fact, this study found that about $40 \%$ of corporate taxi drivers were overweight or obese with a BMI $\left(\mathrm{kg} / \mathrm{m}^{2}\right)$ of 25 or higher, and chronic diseases such as diabetes mellitus $(\mathrm{DM})$, arthritis, and disc disease were higher in corporate taxi drivers than private taxi drivers. This is similar to the results of a previous study, where the rate of overweight and obese taxi drivers with a BMI $\left(\mathrm{kg} / \mathrm{m}^{2}\right)$ of 25 or higher reached $60-80 \%[12,13]$. Furthermore, only $13 \%$ of taxi drivers had normal BMI and abdominal circumference [14]. In addition, the rates of DM and hyperlipidemia in taxi drivers were $19 \%$ and $34.6 \%$, respectively [13], and the rate of those complaining of lower back pain reached 54\% [15]. Increased age and BMI, as well as increased comorbid diseases such as hypertension (HTN), DM, and hyperlipidemia, have been reported to increase the risk of cardiovascular diseases (CVDs) such as myocardial infarction (MI) and angina [14,16]. In particular, MI or angina are thought to further increase the probability of unpredictable accidents due to the sudden onset of symptoms. However, it is thought that the subjective health status of taxi drivers according to the evaluation results of corporate taxi drivers' physical health discomfort and general physical health status in this study can be an objective indicator to reduce the probability of unpredictable accidents as much as possible. Therefore, in preparing policies for taxi drivers, it is necessary to investigate not only objective information on taxi drivers' various physical characteristics, but also subjective health status. In the domestic taxi industry, competition is intensifying due to the global economic crisis and the emergence of various platform transportation businesses [17-20]. Therefore, it is necessary to consider ways to encourage and implement lifestyle changes according to the situation of the domestic taxi industry.

In the case of occupational characteristics, as shown in this study, the number of working days per week and average daily mileage of corporate taxi drivers were greater, and the average number of night shifts per month was also higher. In fact, it was reported that corporate taxi drivers drive at a relatively faster speeds than private taxi drivers [8]. This is thought to be due to the obligation to pay the base payments to operate their taxis, as well as increased speed leading to higher income per unit time. This can be considered as increasing the risk of accidents for corporate taxis. In previous studies, it was reported that the daily driving time is a factor that affects the safety awareness of elderly commercial vehicle drivers [21]. Furthermore, while high-risk taxi drivers had longer taxi driving times, they had shorter breaks [22]. The traffic accidents caused by taxis lead to injuries and deaths among taxi drivers and passengers due to personal damage, and they are accompanied by enormous material damages [23]. In addition, even after traffic accidents, various psychological and emotional damages experienced by the person involved in the 
accident and their families are seen [24,25]. In particular, the damage from traffic accidents is not resolved in the short term and tends to be prolonged [24,25]. Therefore, it is thought that it is necessary to prepare for realistic policies such as a taxi total-pay-receipt system for the taxi industry to prevent repetitive traffic accidents by corporate taxi drivers. The taxi total-pay-receipt system, which was implemented in 2012, implements the abolition of the base payment by corporate taxi drivers and requires them to receive a salary [26] Since 2020, it has been mandatory to implement the taxi total-pay-receipt system. Instead of using the base payment, the term "deposit" has been used, and, when this does not meet the standard, various illegal acts have been detected, such as deducting the monthly salary [27].

In the case of sociocognitive characteristics, this study found that corporate taxi drivers had a higher number of dependent family members, lower monthly household income, and lower income satisfaction, despite having no spouse.

In fact, corporate taxi drivers had increased working days per week and daily mileage, as well as a high percentage of late-night driving, but this was found to be less than $50 \%$ of the target actual business time rate of the Ministry of Land, Infrastructure, and Transport [8]. The actual business time rate is a value obtained by dividing taxi business hours (the hours during which a taxi was driven with passengers) by taxi operating (or driving) time (the hours during which a taxi was driven with passengers + the hours during which the taxi was driven without any passenger) and multiplying by 100. In particular, it is reported that the actual business time rate is only about $60 \%$, despite the increase in the supply of taxis during times of high demand for taxis [8].

The financial burden of taxi drivers leads to excessive driving tasks, which in turn increases the fatigue of the taxi driver. In fact, more than $60 \%$ of taxi drivers report fatigue [28]. In addition, it is reported that the economic burden of taxi drivers affects their safe driving behavior [29,30], and at least $21 \%$ of drivers in fatal accidents reported experiencing sleepiness while driving [31]. In the case of corporate taxis, they are workers under the Labor Standards Act, and there is no problem when they are involved in occupational accidents because they are workplaces subject to occupational accidents. However, in the case of private taxis, occupational accidents can be applied only if they have voluntarily joined the Korea Workers' Compensation and Welfare Service with approval [32]. In the case of taxi drivers, when a traffic accident occurs, most of them are covered by auto insurance rather than occupational accidents. This is because, if taxi drivers treat a traffic accident as an occupational accident, the occupational accident insurance rate may increase, and the taxi company may be subject to supervision by the Labor Office as a workplace with frequent occupational accidents [32].

In fact, after the financial crisis and global economic crisis, the number of vulnerable healthcare groups in Korea increased, and healthcare blind spots further expanded in providing healthcare services. In particular, the low-income class has limited access to healthcare services due to economic factors, and the health gap between economic classes widened further [33].

On another note, hydrogen and electric vehicles, which are showing an increasing trend all over the world, generate less noise and are environmentally friendly [34]. By 2035, the expansion of government support for converting hydrogen and electric vehicles is planned, focusing on public transportation, among business vehicles [35]. However, in recent years, due to such low noise, safety issues for drivers and pedestrians have emerged [34]. Therefore, it is considered that laws and policies should be prepared to prevent the occurrence of various accidents caused by taxis, one of the means of public transportation.

As shown in this study, the rates of mild cognitive impairment and dementia were significantly higher for corporate taxi drivers. Although it is reported that the incidence of cognitive impairment increases with age [36,37], various factors are thought to have an influence on cognitive impairment. In fact, physical and socioeconomic factors are reported to affect traffic accidents and driving behavior, along with cognitive function $[29,30]$. 
Therefore, it is thought that the physical health status and socioeconomic burden of taxi drivers indirectly influenced the degree of cognitive impairment. Since this study did not investigate the psychological health status of taxi drivers, a comprehensive survey of the physical and psychological health status of taxi drivers is considered necessary in the future. Moreover, it is reported that higher social support from the spouse and family leads to a higher likelihood of returning to work after a traffic accident [38]. In particular, as shown in this study, since the proportion of marriages with spouses was lower for corporate taxi drivers than for private taxi drivers, the opinions of spouses and family members need to be reflected in the healthcare policy of taxi drivers.

Since this study had a problem of selection bias due to non-probability sampling, as well as excluding female taxi drivers in the selection of study subjects, there is a limit to generalizing the findings to the characteristics of all corporate and private taxi drivers. However, the number of subjects for this study was not small, and, while it was limited to males, there was no significant difference in the frequency of the number of subjects by age group. Therefore, it can be said that it was a very meaningful approach, in that it explored the problems faced by corporate and private taxi drivers through a comparison of physical, occupational, and sociocognitive characteristics.

\section{Conclusions}

In this study, we compared various physical, occupational, and sociocognitive characteristics of corporate and private taxi drivers in Seoul. According to the results of this study, the below suggestions are made.

First, it is thought that taxi drivers 65 years of age or older should receive additional health checkups, as well as computer simulation tests conducted to maintain the qualifications of taxi drivers. In particular, it is believed that health checkups for taxi drivers over 65 years of age should be legally mandated to expand public healthcare. Furthermore, for taxi drivers under the age of 65 , it is thought that it is necessary to consider methods such as subjective physical and psychological health status evaluations and cognitive dysfunction assessments to replace health checkups.

Second, it is thought that there is a need to prepare an institutional and legal arrangement to reduce the economic burden of taxi drivers. In 2015, the Seoul Metropolitan Government began a policy of obligating a digital tachograph (DTG) to be installed in all taxis $(100 \%)$ in Seoul. However, since DTGs have not yet been installed in other regions outside Seoul, it is necessary to try to solve the problem with the expansion of DTG use in other regions, along with the analysis of large-scale DTG data.

Ultimately, this comparison of the characteristics of corporate and private taxis is expected to serve as evidence for developing tailored policies and programs to improve the health of corporate and private taxi drivers, ensuring the safety of the public.

Author Contributions: Conceptualization, J.O., H.K., and K.K.; methodology, J.O. and H.K.; software, J.O.; validation, K.K.; formal analysis, J.O.; investigation, H.K.; resources, H.K.; data curation, J.O.; writing—original draft preparation, J.O.; writing—review and editing, J.O., H.K., and K.K.; visualization, J.O.; supervision, H.K. All authors have read and agreed to the published version of the manuscript.

Funding: This paper was supported by Konkuk University in 2020.

Institutional Review Board Statement: The study was conducted according to the guidelines of the Declaration of Helsinki and approved by the Institutional Review Board (or Ethics Committee) of Konkuk University (IRB 7001355-202011-E-127).

Informed Consent Statement: All study subjects agreed to participate in the study.

Data Availability Statement: Data were obtained from a secondary provider and are not publicly available.

Acknowledgments: The authors acknowledge any support given which is not covered by the author contributions or funding sections. 
Conflicts of Interest: The authors declare no conflict of interest.

\section{References}

1. Oh, K.S. A Survey on Health Risk between Taxi Drivers and Office Workers. In Proceedings of the Conference of Korean Journal of Health Education and Promotion, Seoul, Korea, 5 December 1997; p. 61.

2. Park, J.M.; Lee, J.B.; Gwak, U.S.; Choi, S.H.; Lee, H.J.; Kim, C.Y.; No, J.H.; Won, J.U. Comparative Study on the Factors Related to Musculoskeletal Symptoms between Taxi Drivers and Bus Drivers. In Proceedings of the Conference of Annals of Occupational and Environmental Medicine, Seoul, Korea, 6 November 2008; pp. 342-343.

3. Jang, H.K.; Hwang, S.H.; Ha, T.S. Factors of taxi drivers' net profits and policy implications. J. Inst. Soc. Sci. 2013, 24, 107-134. [CrossRef]

4. Korea National Joint Conference of Taxi Association. Available online: http://taxi.or.kr/04/01_view.php?no=166 (accessed on 15 June 2019).

5. $\quad$ Kang, S.W.; Park, J.U.; Gu, S.J.; Park, S.J.; Choi, E.J. Taxi Operations in World Cities and Policy Implications for Korea; The Korea Transport Institute: Sejong, Korea, 2013; pp. 1-173.

6. The National Law Information Center. Available online: https://www.law.go.kr/\%EB $\% B 2 \% 95 \% E B \% A 0 \% B 9 / \% E C \% 97 \% A C \%$

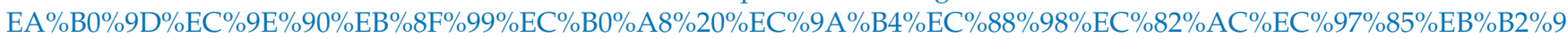
5\%20\%EC\%8B $\% 9$ C $\%$ ED $\% 96 \% 89 \% E A \% B 7 \% 9 C \% E C \% B 9 \% 99$ (accessed on 31 January 2021).

7. The Chosun Ilbo. Promotion of Lower Insurance Premiums for Private Taxi Drivers. Available online: https://biz.chosun.com/ site/data/html_dir/2013/05/18/2013051800149.html (accessed on 5 February 2021).

8. An, K.J. Seoul Taxi Use and Operation Status and Improvement Plan. Seoul Inst. 2015, 186, 1-19.

9. Hwang, G.H.; Yoon, D.S. A comparative analysis of the operational conditions of corporate -owned and owner-driver taxies using tachometer data. J. Korean Soc. Transp. 2006, 24, 45-54.

10. Yu, J.H.; Park, S.W.; Han, D.J. A Comparative Analysis of Taxi Accident by Types. Traffic Technol. Policy 2018, 15, 40-48.

11. Yang, D.W.; Chey, J.Y.; Jo, B.R.; Kim, S.Y.; Kim, B.S. The Development and Validation of Korean Dementia Screening Questionnaire (KDSQ). J. Korean Neurol. Assoc. 2002, 20, 135-141.

12. Ramukumba, T.S.; Mathikhi, M.S. Health Assessment of Taxi Drivers in the City of Tshwane. Curationis 2016, 39, 1-7. [CrossRef]

13. Lim, S.M.; Chia, S.E. The Prevalence of Fatigue and Associated Health and Safety Risk Factors among Taxi Drivers in Singapore. Singap. Med J. 2015, 56, 92-97. [CrossRef]

14. Martin, W.P.; Sharif, F.; Flaherty, G. Lifestyle Risk Factors for Cardiovascular Disease and Diabetic Risk in a Sedentary Occupational Group: The Galway Taxi Driver Study. Ir. J. Med Sci. 2016, 185, 403-412. [CrossRef]

15. Wang, M.; Yu, J.; Liu, N.; Liu, Z.; Wei, X.; Yan, F.; Yu, S. Low Back Pain among Taxi Drivers: A Cross-Sectional Study. Occup. Med. 2017, 67, 290-295. [CrossRef] [PubMed]

16. Elshatarat, R.A.; Burgel, B.J. Cardiovascular Risk Factors of Taxi Drivers. J. Urban Health 2016, 93, 589-606. [CrossRef] [PubMed]

17. Kim, B.O. A Study on Uber Taxi and the Fit of It. Law Rev. 2015, 46, 99-134.

18. Choi, B.G. A Study on Car-Sharing and Onerous Transport or Not. Ilk. Law Rev. 2017, 38, 429-454. [CrossRef]

19. Lee, K.J.; Park, J.H. The Impact of the Mobile Application on Off-Line Market: Case in Call Taxi and Kakao Taxi. Inf. Syst. Rev. 2016, 18, 141-154. [CrossRef]

20. Kim, D.K. Insurance Issues for Commercialization of Robo-Taxi. Korean Insur. Low J. 2019, 13, 235-263. [CrossRef]

21. Jeon, B.J. An Empirical Study on the Safety Consciousness of Elderly Drivers: Comparison of Commercial and Non-Commercial Drivers. J. Korea Contents Assoc. 2015, 15, 223-232. [CrossRef]

22. Li, M.K.; Yu, J.J.; Ma, L.; Zhang, W. Modeling and Mitigating Fatigue-Related Accident Risk of Taxi Drivers. Accid. Anal. Prev. 2019, 123, 79-87. [CrossRef]

23. Korea Insurance Development Institute: INsis (Insurance Statistics Information Services): Car Insurance: Damage Situation 2020. Available online: https:/ / incos.kidi.or.kr:5443/insCar/selStattbleDetail.do\# (accessed on 15 January 2020).

24. Lee, M.I.; Park, S.H.; Kim, S.H.; Kim, J.M.; Kim, H.R. The Relationship between Psychiatric Consequences and Injury Severity Following Traffic Accidents. Korean J. Psychosom. Med. 2004, 12, 66-75.

25. Jeon, B.J.; Lee, S.J. Mediation Effects of Post-Traumatic Growth on the Relation between Traffic Accident Trauma and Safety Consciousness of Aged Taxi Drivers. Korean Soc. Wellness 2018, 13, 467-478. [CrossRef]

26. Ministry of Land Infrastructure and Transport. Guideline for the Taxi Total-Pay-Receipt System. Available online: https: / / www.molit.go.kr/USR/policyTarget/m_24066/dtl.jsp?idx=1011 (accessed on 31 January 2021).

27. Yun, Y.S. Wage-related scheme of total pay-receipt system in the taxi industry. Res. Humanit. Soc. Sci. 2018, 675-715. [CrossRef]

28. Meng, F.; Li, S.; Cao, L.; Li, M.; Peng, Q.; Wang, C.; Zhang, W. Driving Fatigue in Professional Drivers: A Survey of Truck and Taxi Drivers. Traffic Inj. Prev. 2015, 16, 474-483. [CrossRef]

29. Murray, K.E.; Buul, A.; Aden, R.; Cavanaugh, A.M.; Kidane, L.; Hussein, M.; Eastman, A.H. Occupational Health Risks and Intervention Strategies for Us Taxi Drivers. Health Promot. Int. 2019, 34, 323-332. [CrossRef] [PubMed]

30. Mehri, M.; Khazaee-Pool, M.; Arghami, S. Phenomenology of Being a Safe Taxi Driver. BMC Public Health 2019, 19, 1-12. [CrossRef] [PubMed] 
31. Tefft, B.C. Prevalence of Motor Vehicle Crashes Involving Drowsy Drivers, United States, 2009-2013 (2014). Available online: http:/ / citeseerx.ist.psu.edu/viewdoc/download?doi=10.1.1.684.6347\&rep=rep1\&type=pdf (accessed on 20 February 2020). [CrossRef]

32. The Namhaean Newspaper. Is Car Insurance Advantageous in Case of a Taxi Driver Traffic Accident or Occupational Accident Insurance? Available online: http:/ / www.nhanews.com/news/articleView.html?idxno=56075 (accessed on 5 February 2021).

33. Oh, Y.H. Problem with and policy agenda for public health services in Korea. Health Welf. Policy Forum 2013, 23, 62-82.

34. Pardo-Ferreira, M.C.; Torrecilla-García, J.A.; Heras-Rosas, C.D.L.; Rubio-Romero, J.C. New Risk Situations Related to Low Noise from Electric Vehicles: Perception of Workers as Pedestrians and Other Vehicle Drivers. Int. J. Environ. Res. Public Health 2020, 17, 6701-6716. [CrossRef]

35. Ministry of Land Infrastructure and Transport. Advancing the Hydrogen Society by Building a Preemptive Charging Infrastructure. Available online: http:/ / www.molit.go.kr/USR/NEWS/m_72/dtl.jsp?id=95078906 (accessed on 31 January 2021).

36. Shin, S.G.; Cho, M.S. A Study on Traffic Accident Prevention through Older Driver's Characteristics Analysis. J. Korean Public Police Secur. Stud. 2010, 7, 157-185. [CrossRef]

37. Oh, J.S.; Ryu, J.B.; Lee, W.Y. Major Factors Affecting Driving and Psychosocial Characteristics of Elderly Drivers. Traffic Res. 2016, 23, 35-48. [CrossRef]

38. Kenardy, K.; Heron-Delaney, M.; Warren, J.; Brown, E. The Effect of Mental Health on Long-Term Health-Related Quality of Life Following a Road Traffic Crash: Results from the UQ SuPPORT Study. Injury 2015, 46, 883-890. [CrossRef] [PubMed] 